\title{
Willingness to pay for an Integrated Pest Management Strategy for Suppression of Citrus Infesting False Codling Moth, African Citrus Trioza and Greening Disease Among Citrus Producers in Kenya
}

\author{
Gitahi Dorothy W.* \\ Egerton University, Department of Agricultural Economics and Agribusiness Management \\ Egerton University, P.O BOX 536, Egerton \\ Muriithi Beatrice W. \\ International Centre for Insect Physiology and Ecology (icipe), P.O. Box 30772-00100 Nairobi, Kenya
}

George Owuor

Egerton University, Department of Agricultural Economics and Agribusiness Management Egerton University, P.O BOX 536-20115, Egerton

Diiro Gracious

International Centre for Insect Physiology and Ecology (icipe), P.O. Box 30772-00100 Nairobi, Kenya

Mohamed Samira

International Centre for Insect Physiology and Ecology (icipe), P.O. Box 30772-00100 Nairobi, Kenya

\begin{abstract}
${ }^{2}$ Funding
This research was financed by the German Ministry of Economic Cooperation and Development German cooperation (BMZ) through the project Strengthening Citrus Production Systems through the Introduction of Integrated Pest Management (IPM) Measures for Pests and Diseases in Kenya and Tanzania (SCIPM) (Project no:14.1432.5-001.00/Contract no.: SCIPM 81180346) through the International Centre of Insect Physiology and Ecology (icipe). We also acknowledge the icipe core funding provided by the by UK Aid from the Government, the Swedish International Development Cooperation Agency (Sida), the Swiss Agency for Development and Cooperation (SDC), and the Kenyan Government. The views expressed herein are those of the authors and do not necessarily reflect the opinion of the donors.
\end{abstract}

\section{${ }^{3}$ Acknowledgement:}

Dorothy would wish to thank the International Centre for Insect Physiology and Ecology (icipe) for granting her the MSc fellowship to conduct this research, and the Department of Agricultural Economics and Agribusiness Management, Egerton University for the guidance throughout her MSc course. The authors also wish to recognize the enumerators' effort and the smallholder citrus farmers in the study sites for voluntarily participating in the survey.

\begin{abstract}
Citrus production in Kenya has been declining due to myriad of challenges, top among them, being pest and disease infestations, with most severe ones noted to be the African citrus triozid (ACT) and false codling moth (FCM) pests and Huanglongbing (HLB) disease. In order to strengthen citrus industry in the sub-Saharan Africa, including in Kenya, the International Centre of Insect Physiology and Ecology (icipe) and its partners are proposing an alternative strategy for addressing these pests and diseases, other than the often-used application of synthetic chemicals. The integrated pest management (IPM) approach aims at reducing citrus losses attributed to FCM, ACT and greening disease while conserving the environment. This study was carried out ex ante introduction of the IPM strategy to access farmers' knowledge, perception, and practices of the pests and disease, and their willingness to pay for the IPM strategy. A household level survey involving 324 randomly selected citrus producers in Machakos and Makueni Counties of Kenya was conducted using semi-structured questionnaires. The findings show that farmers used indigenous traditional practices, as well as synthetic pesticides to manage the three abiotic constraints, mainly using their own acquired knowledge on pest and disease control and a few consulting their neighbors. On average, the respondents were willingness to pay KES 7,766 for FCM and KES 10,639 for IPM package for ACT and greening disease per acre per season. Area of land under crop, knowledge, and practices of managing citrus pests and diseases and access to extension services had a significant effect on the willingness to pay for integrated pest management approach. Policy effort should focus on strengthening extension services to promote awareness and use of the IPM strategy
\end{abstract}


Keywords: integrated pest management, citrus, willingness to pay, Kenya, Africa

DOI: $10.7176 / \mathrm{JESD} / 10-2-06$

\section{INTRODUCTION}

Agriculture remains the main economic activity in Kenya, with horticulture representing $21 \%$ of exports and providing $40 \%$ of labor force in the country ("Ministry of Agriculture, MOA, 2010). The sub-sector is also source of employment, income, and food and nutrition security in many rural families. Although produced mainly by smallholders, citrus production is the third most important fruit after banana and mangoes in terms of foreign exchange earnings through exports. Citrus is a dependable source of vitamin C (FPEAK, 2010). The main types of citrus fruits produced in Kenya includes pummelons, limes, sweet oranges, tangerines and grapes and the basic acid verities such as citrons, limes, and lemons (MOA, 2010).

Over the last 10 years, production of citrus fruits has been declining, to a low of between 4-10 tons per hectare in 2006, while the potential production is estimated to be between 7.9 to 8.5 tons per hectare (MOA, 2010). Although faced with numerous challenges including low productivity, low input use among others, the sub-sector's low performance is attributed to pests and diseases infestation. Key among the diseases is the huanglongbing (HLB), otherwise called the greening disease. The disease is caused by a vector transmitted pathogen that causes yellow shooting of the plant that are different from the typical green shading of citrus plant leaves (Sastry \& Zitter, 2013). HLB is considered as the most devastating disease of citrus which can cause between 25 to $100 \%$ citrus yield loss (Bové, 2006; Kilalo et al., 2009; Pole et al., 2010). In addition to reducing yield through continues fruit drop, dieback, and tree stunning, the quality of fruits that remain on the trees is greatly comprised. Significant citrus pests include the African Citrus Triozid (ACT) and False Codling Moth (FCM). ACT transmits lethal microorganisms known as Candidatus Liberibacte Africanus (CLaf) responsible for the greening disease. Besides, direct feeding by ACT can cause the death of developing citrus terminals or abscission of leaves and up to $65 \%$ of such infestations are common. FCM larvae on the other hand directly damage citrus by drilling into fruits, causing them to drop prematurely, resulting in 34-68\% fruit loss (Manene, 2010; Ekesi, 2012).

In Africa, management of pests and disease is mainly dependent on the use of synthetic pesticides. Without alternative control mechanisms, farmers tend to overuse (misuse) synthetic pesticides by increasing the spraying frequency and/or blending different pesticide brands to make them more effective (Macharia et al., 2008). Since chemical control methods are associated with negative outcomes on human and environmental health, alternative measures such as Integrated Pest Management (IPM) are more acquiring attention in agricultural production (Norton et al., 2009). IPM is a pest management strategy that comprises use of pest control approaches that ensures favorable economic, ecological and sociological consequences (Blake et al., 2007). The approach includes a combination of biological, chemical and cultural methods. Such strategies have been used to control citrus pests in some regions in the world for instance in South Africa, which hosts a wide range of citrus pests than most of the African countries (Charleston et al., 2003). IPM strategies have also been widely used in other crops to manage pests and diseases, for example the fruit fly IPM strategy developed and disseminated for control of mango fruit flies in the Sub-Saharan Africa ( Billah, Mansell, De Meyer, \& Goergen, 2009; Ekesi, Mohamed, \& Tanga, 2014; Lux, Ekesi, Dimbi, Mohamed, \& Billah, 2003). While there are many benefits associated with use of IPM approaches, the level of adoption in the Sub-Saharan Africa is slow with only an insignificant percentage of growers embracing the strategy. Divergences in knowledge concerning the integrated pest management technology and resource constraints have been noted as some of the causes for the limited uptake, especially among smallholder farmers (Norton et al. (2009).

The perceptions of an IPM approach vary greatly among farmers. Some farmers perceive IPM strategies to be cost-effective only on large scale productions and thus get discouraged to try them in their small farms (Muriithi et al., 2016). IPM approach has nevertheless been acknowledged as an effective method in reducing insect damage in various horticultural enterprises. For instance, in their study in Embu County in Kenya, Kibira et al. (2015) estimated 54\% reduction in mango losses among farmers who adopted an IPM strategy for suppression mango fruit flies, in comparison with those who had not adopted. The strategy comprise of five components including biological control (bio pesticides and parasitoid), cultural control (orchard sanitation), food bait spray and fruit fly traps (Ekesi 2015; Muriithi et al., 2016). An ex-ante study for the same strategy revealed that 66 percent of the interviewed farmers were willing to pay 50 percent over and above the stated price of the fruit fly IPM package as they perceived it to be more efficient and effective compared to synthetic pesticides (Muchiri, 2012). Application of IPM reduces pesticide expenditure and thus improving farm enterprise profitability (Varela et al., 2006;. Muriithi et al., 2016; Kibira et al., 2015). In the sub-Saharan Africa (SSA) and outside of the Republic of South Africa (RSA), such IPM strategies for management of citrus infesting FCM and ACT are lacking, attracting widespread use of pesticides, that impact negatively on their natural enemies, besides causing harmful effects to human health and the environment.

The international Centre for Insect Physiology and Ecology (icipe) in collaboration with partners from 
Africa and Europe, plan to develop and disseminate IPM measures for citrus infesting FCM, ACT and greening disease in Kenya and Tanzania. The project aims at strengthening the citrus production systems to improve productivity and yield and enhance the economic welfare of small and medium scale producers in the two countries. The current study was conducted within this project to assess the farmers' knowledge, attitude and practices of ACT, HLB and FCM in Kenya, and determine their willingness to pay for IPM measures to suppress these constraints. Since ACT vectors HLB disease, the two constraints are addressed using the same IPM package, while a second package addresses the FCM pest. The icipe proposed IPM strategy for suppression of ACT and HLB comprise of use of (1) use of bio pesticide, (2) traps and attractants for ACT, (3) planting disease free materials, and (4) cultural method that involves identifying and removing diseased plant parts or chopping down the tree. The FCM strategy on the other hand comprise of (1) use of bio pesticide for soil inoculation (MET 69), (2) pheromone traps, (3) last-call pheromone, and (4) orchard sanitation through removal of fallen infested fruits. Some of these components are already in use for management of these pests and disease in South Africa (Urquhart, 1999).

This study contributes to the limited literature on socio-economics of citrus farming in Kenya in two ways. First, it is the first study to our knowledge that accesses the knowledge and perceptions of farmers as regards to the ACT, HLB and FCM. Knowledge about the symptoms of the pests and diseases and their transmission, as well as perceived level of infestation, is important for deciding the most appropriate control practices. Smallscale farmers however may lack such knowledge and may have incorrect perceptions, which may accelerate the problem, resulting to loss of all harvestable yields. It is therefore important to understand what farmers know about the pests and disease, their perceptions about crop yield losses, and control methods that they use and perceived effectiveness of these methods. Second, it is the first one to evaluate the ex-ante willingness to pay (WTP) for the proposed IPM measures for the target citrus pests and diseases. The WTP estimations are important for policy, since they mirror the importance of the technology to the welfare of the farmers.

The next section presents the methodology of the study including the description of the study area, survey design and data collection and the econometric approach. Section three provides the results while section 4 presents the conclusion and recommendations of the study.

\section{METHODOLOGY}

\subsection{Study site}

This study was conducted in two purposely selected counties in Kenya where citrus are predominantly produced (namely Machakos and Makueni) (Figure 1). Over $10 \%$ of the farming households in these counties grows citrus for commercial purposes (Ministry of Agriculture, 2010). The regions are featured by fertile, dark reddish brown to dark brown and friable clay with sleek best soils which are conducive for citrus production (Jaetzold et al., 2006). They comprise of lower highlands, upper midlands, and lower midlands that favor different types of citrus fruits. The rainfall is bimodal with the long rain season occurring between March-June and the short rain season between October-December. Citrus is a perennial crop that is harvested once in a year. Similar to many citrus producing areas in Kenya and Sub-Saharan Africa in general, citrus production in the area has been declining over the years due to heavy pests and disease infestations. 
Figure 1: Map of study Area

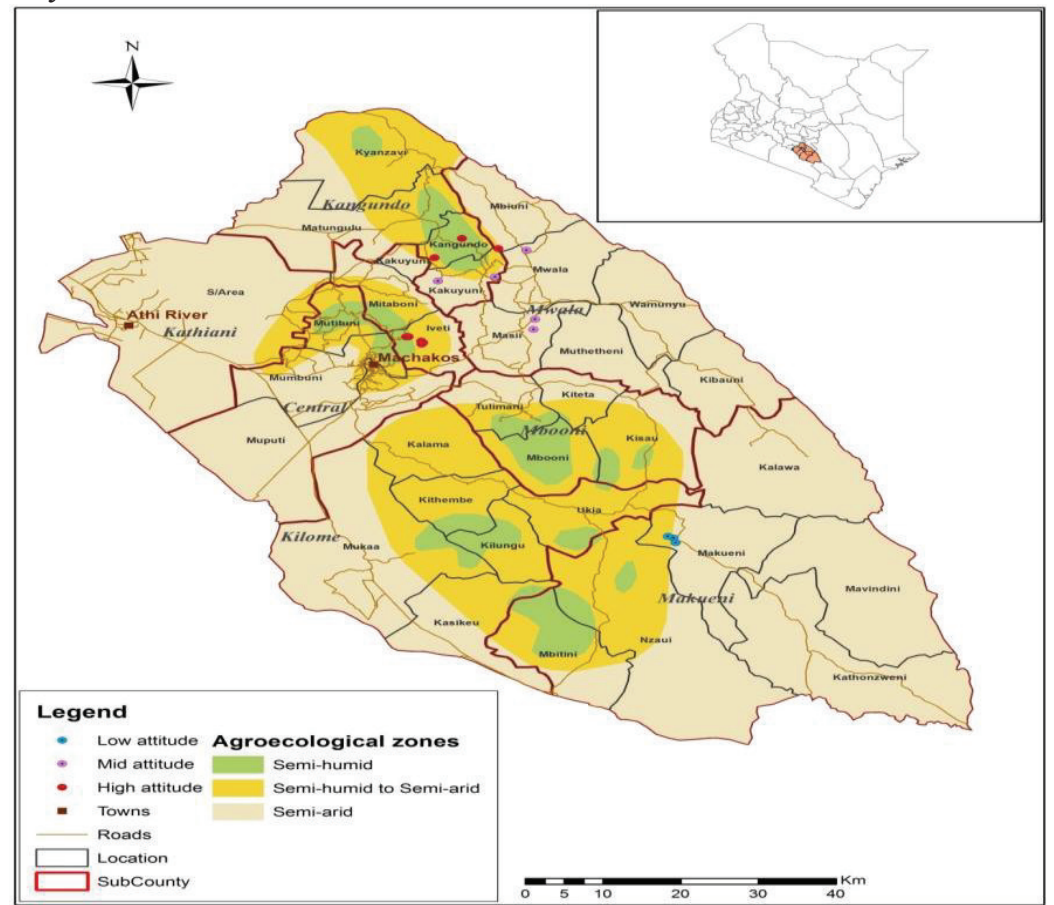

Source: Cartography by the Regional Centre for Mapping of Resource for Development, Egerton University

\subsection{Survey}

A multistage sampling procedure was used to select the sample. First stage involved selection of the two counties described above. In the second stage, three sub-counties were purposively selected within the two counties where citrus production is mainly practiced. These were Kangundo and Mwala sub-Counties in Machakos County and Makueni Sub-County in Makueni County. The next step was to select mango-growing wards and villages in each sub-county. This was done in collaboration with the local agricultural extension workers who developed a census of citrus growers in the selected wards and villages who had at least 5 or more mature citrus trees in each village, from which a sample of 324 citrus growing households. To ensure that every household in the target population had an equal chance of being included in the sample, Probability Proportional to size (PPS) sampling technique was used to randomly select the villages and the sample of households, who were then interviewed by well-trained enumerators, who understood the local language and were supervised by a researcher from icipe.

A semi-structured questionnaire was used to collect data using tablets. Data collection was conducted between November and December of 2017 recalling the information for the preceding (2016/2017) citrus season. Detailed information on farmers' demographics, socio-economic features, citrus production and marketing including knowledge, perceptions, and practices as regards FCM, ACT and greening disease infestations, input accessibility, information access and social capital parameters. In addition to the household survey, qualitative perception information was collected through key informant interviews and informal farmer group discussions in the study areas.

To elicit the revealed preferences for the IPM strategies for citrus FCM, ACT and greening disease, farmers were first asked if they had ever heard about the different IPM components highlighted in section one of this paper. Colored images of some the components were shown to the farmers to ensure they understood the IPM components. Whether they were aware or not, they were presented with a brief explanation of the scientific background of the IPM approach of pest and disease management. This involved outlining the negative effects associated with use of synthetic pesticides, followed by the benefits of adopting the IPM approach as an alternative method of controlling pests and diseases. The cost of each IPM package, calculated by the researcher in collaboration with biological scientists at icipe was then presented to the farmers. A standard initial IPM package for FCM would cost a farmer Kenya shillings (KES) 5,560 per acre per year, while that of ACT (and greening disease) would cost KES. 5,180 per acre per year. As this study followed a double-bounded contingent valuation method to elicit farmer's preferences, these amounts were adjusted upward or downwards as we will explain in detail in the next section. 


\subsection{Empirical analysis}

2.3.1 Conceptual approach for the farmers' willingness to pay for IPM measures for management of ACT, FCM, and HLB

The study applied contingent valuation (CV) method to estimate the willingness to pay for IPM measures for FCM and ACT/HLB among citrus growers in Machakos and Makueni counties. The CV approach is widely used to elicit preferences in different fields, including agriculture, market, and environmental studies (Carson et al., 2001; Kimenju \& De Groote, 2008; Kassie et al., 2017). The approach is based on utility maximization theory, which assumes that the farmer will adopt the technology if the utility expected, is higher than what is currently in use, subject to production constraint. The CV method can either be single bounded, double bounded or multiple bounded (Hanemann \& Kanninen, 1998). Single bounded choice is made of only one willingness to pay question, where the respondent accepts or rejects the offer. The double bounded model comprises of a follow up question, after the respondent's answers to the first offer, while the multiple-bounded approach provides multiple offers. While the single bounded approach is easy to apply, it requires a large sample size and may not provide WTP efficient estimates (Hanemann \& Kanninen, 1998). Although the multiple bounded approach is particularly useful when initial information of possible levels of the bids is inadequate, the approach is challenged due to possible bias during the design, which may be influenced by the levels and number of bids considered (Whitehead, 2002; Kimenju \& De Groote, 2008). By providing a second chance, double bounded approach provides more information about the respondent's willingness to pay and, therefore more efficient WTP estimates (Hanemann et al., 1991).

Subsequently, this study adopted the double bounded approach, since the levels of the bids were known a priori, and to provide efficient estimated of the WTP for the citrus pests and disease. In this approach, a cirtus farmer is preseted with two price offers or bids, where the second one is condictional of the response of the first. Such that if the faremr says "yes" to the first price offer (standard price of the IPM) $\left(\beta_{I}\right)$, a higher price is presnted on the second bid $\left(\beta_{U}\right)$., but if the farmer says "no" to the first offer, a lower price is presented $\left(\beta_{L}\right)$. In that case, there were four possible outcomes; YY if the farmer responds "yes" to the first and second offers, YN if the first answer is "yes" followed by "no" in the second offer, NY if "no" answer to the first offer and "yes" to the second, and NN if "no" to both offers (Flachaire \& Hollard, 2006). The probabilities of these outcomes can be denoted as $\pi^{y y}, \pi^{y n}, \pi^{n y}$, and $\pi^{n n}$ and respectively. The first price offer $\left(\beta_{I}\right)$, was the standard price of the IPM measures as given in the introduction section, while the second offer (lower or higher than the first one) were different amounts where only one amount picked randomly by the enumerator was presented to the farmer, conditional on the answer to the first offer. The willingness to pay $G(\beta, \theta)$ distribution, for the four possible outcomes can be expressed as follows

$$
\begin{aligned}
& \pi^{y y}\left(\beta_{I} \beta_{U}=\operatorname{Pr}\left(\beta_{I}<\max W T P \geq \beta_{U}\right)=\operatorname{Pr}\left(\beta_{U} \leq \max W T P\right)=1-G\left(\beta_{U}, \theta\right)\right. \\
& \pi^{y n}\left(\beta_{I} \beta_{U}=\operatorname{Pr}\left(\beta_{I} \leq \max W T P \geq \beta_{U}\right)=G\left(\beta_{U}, \theta\right)-G\left(\beta_{I}, \theta\right)\right. \\
& \pi^{n y}\left(\beta_{I} \beta_{L}=\operatorname{Pr}\left(\beta_{I}>\max W T P \leq \beta_{L}\right)=G\left(\beta_{I}, \theta\right)-G\left(\beta_{L}, \theta\right)\right. \\
& \pi^{n n}\left(\beta_{I} \beta_{L}=\operatorname{Pr}\left(\beta_{I} \geq \max W T P<\beta_{L}\right)=\operatorname{Pr}\left(\beta_{L}>\max W T P\right)=G\left(\beta_{L}, \theta\right)\right.
\end{aligned}
$$

Where WTP is the maximum willingness to pay for the IPM by the farmers, with parameter vector to be estimated. In this study, the IPM is assumed to be logistically distributed among the farmers and therefore, $G\left(B_{\bullet}\right)=\left[1+e^{v}\right]^{-1}$ where $v=\left(\alpha-\rho B_{\bullet}\right)$. The parameters of the index function $\alpha$ and $\rho$ were estimated by maximizing the likelihood function. Given the above expressions (Eqns (1)-(4), the log likelihood function for the double dichotomous model can be written as follows;

$$
\begin{aligned}
& \operatorname{LnL}(\theta)=\sum_{n=1}^{N}\left\{d^{y y} \ln \pi^{y y}\left(B_{I}, B_{U}\right)+d^{y n} \ln \pi^{y n}\left(B_{I}, B_{U}\right)+d^{n y} \ln \pi^{n y}\left(B_{I}, B_{L}\right)+\right. \\
& \left.d^{n n} \ln \pi^{n n}\left(B_{I} B_{L}\right)\right\}
\end{aligned}
$$

Where $d^{\bullet}$ is the binary indicator function that assumes the value of 1 when the respective responses will be chosen and 0 otherwise. The log-likelihood function is maximized using logistic function, and the mean willingness to pay is calculated as $\sigma / \rho$, estimated using bootstrapped standard errors (Hanemann et al., 1991). 


\subsubsection{Determinants of the willingness of farmers to pay for the IPM measures for FCM and ACT/HLB}

For the evaluation of the WTP for the FCM and ACT/HLB, we estimate the two models using maximum likelihood technique as expressed in Eqn. (5). It is assumed that WTP to influenced by a vector of explanatory variables $\boldsymbol{x}$. Thus

$$
W T P=\alpha+\boldsymbol{\tau} \boldsymbol{x}^{\prime}+\boldsymbol{\epsilon}
$$

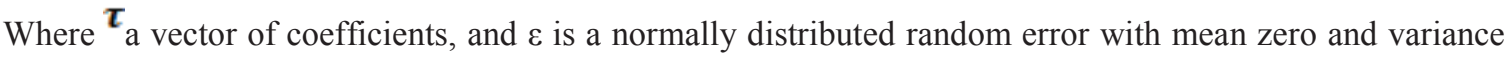
$\sigma^{2}$

The coefficient estimates can be interpreted as the marginal effects of the explanatory variables on WTP. The mean WTP then can be defined as $E(W T P)={ }^{\wedge} \bar{\gamma}$ expected to influence the willingness to pay for the IPM measures for citrus infesting FCM, ACT/HLB were obtained from theoretical literature on agricultural technology adoption. These includes household characteristics such as age, gender and education of the household head and household size; household resources including proportion of income derived from the target crop (citrus), livestock ownership and farm size; household access to services including access to extension and distance to the market; and social capital including membership in farmer organizations and access to citrus production contract. Knowledge, attitude and practice in regard to FCM, ACT and HLB were also considered important in determining farmers' willingness to pay for the IPM measures.

The knowledge score was attained by posing questions relating to the pests (FCM and ACT) and disease (HLB) whose replies were coded as one for a correct response while the wrong response or 'don't know' was coded as zero. The correct responses were summed up to give a knowledge score and expressed as a percent. The questions included correct identification of the pests and disease, the infestation symptoms and how it is spread. Awareness regarding use of non-pesticides measures such as IPM was also probed. Attitudes concerning the pests and diseases were measured descriptively where farmers were presented with various perception questions such as perceived severity of the pests/disease, and perceived damage caused by these constraints. The answers were also aggregated together and expressed as a percentage. Practices refer to the authentic actions that farmers took to control their pest and disease problems. For each of the pests and disease, farmers were asked whether they tried to control it and what methods they used if they did, and how effective they perceived those management measures. Similarly, the answers were aggregated to a common score and expressed in percentage.

\section{RESULTS AND DISCUSSIONS}

Descriptive and empirical analyses were used to analyze the coded data. Statistical Package for Social Sciences (SPSS) and Stata were used to analyze the data..

\subsection{Selected farm and farmer characteristics of the sampled households}

Table 1 present summary statistics of the explanatory variables used in the model. We present the results for the full samples, and by County. On average, each family comprised of about 3 adult equivalent members which, implying that most producers have small families. About $92 \%$ of the sampled households had a male head, while the rest had female heads. The average age of households heads were 56 years, with heads from Makueni County being younger than those of Machakos County. With respect to household resources, on average, the households owned 2.14 tropical livestock units (TLU), and about 2.75 acres of land. Respondents from Makueni reported bigger land size but smaller herds of livestock in comparison to those from Machakos County. On average, farmers owned 120 citrus trees, which occupied about 0.87 acres of arable land. Majority of the farmers intercropped citrus trees with other crops while a few had pure stands. In terms of access to information, contact with agricultural extension service providers was very low, with an average of $46 \%$ farmers reporting to have had contact with the providers for the past 12 months. The low extension contact can be explained by the long distance reported to the nearest agricultural extension office, which was on average 79 walking minutes. The average walking distance to the input (village) market was about 27 minutes, while to the main output market was about 60 minutes. With respect to social capital networks, only 15 percent of respondents reported to be members of farmer group and $2 \%$ had a citrus production contract, implying that this form of social capital has not been widely embraced in the study areas. Such platform enhances farmers' bargaining power, access to markets and reduce their vulnerability to exploitation by middle men (Muchiri, 2012). 
Table 1: Selected household characteristics of the citrus growers in Machakos and Makueni Counties

\begin{tabular}{|c|c|c|c|c|c|c|}
\hline \multirow[t]{2}{*}{ Characteristics } & \multicolumn{2}{|c|}{$\begin{array}{c}\text { Full sample } \\
(\mathbf{n}=324)\end{array}$} & \multicolumn{2}{|c|}{$\begin{array}{c}\text { Machakos } \\
(n=190)\end{array}$} & \multicolumn{2}{|c|}{$\begin{array}{l}\text { Makueni } \\
(\mathrm{n}=134)\end{array}$} \\
\hline & Mean/ percent & SD & $\begin{array}{l}\text { Mean/ } \\
\text { percent }\end{array}$ & SD & $\begin{array}{l}\text { Mean/ } \\
\text { percent }\end{array}$ & SD \\
\hline Household characteristics & & & & & & \\
\hline Age of the household head (years) & 56.14 & 12.34 & 58.53 & 12.23 & 52.75 & 111.73 \\
\hline Household size (adult equivalent) & 2.71 & 0.85 & 2.55 & 0.83 & 2.93 & 0.84 \\
\hline Gender of household head ( $\%$ male $)$ & 91.98 & & 91.05 & & 93.28 & \\
\hline Marital status (\%Married) & 90.74 & 0.29 & 89.47 & 0.26 & 92.54 & 0.31 \\
\hline $\begin{array}{l}\text { Livestock ownership (Tropical } \\
\text { livestock units) }\end{array}$ & 2.14 & 1.60 & 2.29 & 1.70 & 1.68 & 1.20 \\
\hline Owned farm size (acres) & 2.75 & 3.01 & 2.76 & 3.11 & 2.71 & 2.79 \\
\hline Citrus trees (counts) & 120 & & 102 & & 138 & \\
\hline $\begin{array}{l}\text { Proportion of land under citrus } \\
\text { production }\end{array}$ & 0.87 & 1.47 & 0.79 & 1.33 & 0.98 & 1.64 \\
\hline $\begin{array}{l}\text { Household access to services } \\
\text { household received extension contact } \\
(1=\text { Yes, } 0=\mathrm{NO})\end{array}$ & 0.46 & 0.50 & 0.54 & 0.50 & 0.34 & 0.47 \\
\hline $\begin{array}{l}\text { Distance to the nearest agricultural } \\
\text { extension office (walking minutes) }\end{array}$ & 79.72 & 53.28 & 76.43 & 56.47 & 84.35 & 48.25 \\
\hline $\begin{array}{l}\text { Distance to the village market from } \\
\text { residence (walking minutes) }\end{array}$ & 27.39 & 26.38 & 25.84 & 26.67 & 29.58 & 25.90 \\
\hline $\begin{array}{l}\text { Distance to the nearest main output } \\
\text { market (walking minutes) } \\
\text { Social capital }\end{array}$ & 63.35 & 57.98 & 59.48 & 63.16 & 68.82 & 49.42 \\
\hline $\begin{array}{l}\text { Membership to farmer based } \\
\text { association }(1=\text { Yes, } 0=\mathrm{No})\end{array}$ & 15.43 & & 20.0 & & 8.96 & \\
\hline $\begin{array}{l}\text { Have a citrus production contract } \\
(1=\mathrm{Yes}, 0=\mathrm{No})\end{array}$ & 1.23 & & 1.05 & & 1.49 & \\
\hline
\end{tabular}

3.2 Willingness to pay for an integrated pest management strategy

To calculate the WTP, the logistic model Equation (5) was estimated. The results for the average WTP are given in Table 2. As shown in Table 2, aggregate willingness to pay for the FCM IPM package was KES 7,766 per acre per season, while that African citrus trioza and greening disease was KES 10,638 per acre per season. This was $40 \%$ and $105 \%$ higher than the price offered for a standard package of the IPM for suppression of FCM and ACT/HLB respectively, implying that potential demand for the IPM technology among the citrus farmers. The finding also suggests that farmers understood clearly the apparent benefits associated with use of IPM as alternative to the conventional pesticides, as was clearly explained by the enumerators.

Table 2: Mean willingness to pay for false codling moth, African citrus trioza and the greening disease

\begin{tabular}{llcc}
\hline & Coef. & $\mathbf{Z}$ & $\mathbf{P}>\mathbf{Z}$ \\
\hline FCM & $7766.31(5560)$ & $5.460^{* * *}$ & 0.00 \\
ACT/HLB & $10638.77(5180)$ & $7.09^{* * *}$ & 0.00 \\
\hline
\end{tabular}

\subsection{Factors influencing willingness to pay}

Table 3 presents the factors affecting willingness to pay for the IPM packages. Beginning with household characteristics, the results show that education of the household heads is positively related to WTP for both FCM and $\mathrm{ACT}$, although the variable is only significant at $10 \%$. The finding agrees with agricultural adoption literature that educated farmers are better able to receive and interpret information on new innovations and hence willing to pay higher price for the innovation.

With respect to household resources, the proportion of income a farmer gained from the fruits was positively related to a farmer's willingness to pay for the ACT/HLB IPM strategy, and was significant at 5 percent. Increase of the income by 1 percent increased the WTP to pay for ACT/HLB strategy by about KES 32 holding other factors constant. It indicates that farmers who received higher income from citrus production, probability with commercial orientation of the fruit enterprises, would be more likely to adopt the IPM package. This finding agrees with previous research that U.S. farmers with higher incomes were willing to pay more for advanced bio pesticides (Adetonah, Coulibaly, Nouhoheflin, Kooyman, \& Kpindou, 2008). In contrast to our expectation the size of land under citrus fruits was negatively related to the WTP of either package. Possible 
explanation of this finding is that farmers with big citrus farms may have enough resources to invest in synthetic pesticides, in comparison to small scale resource constraint farmers who may want to try cheaper pest management options such as IPM.

As expected, having contact with extension officer positively influence the WTP for both ACT/HLB and FCM, suggesting that extension services provide an important channel for disseminating agricultural information in the area. Subsequently, the services can be utilized to disseminate information regarding the IPM strategies. Knowledge about pests was positive and significantly related to farmer's willingness to pay for the FCM IPM package. This finding implies that farmers who were informed about the pest were more likely to try the alternate agricultural practice (Muchiri, 2012). Attitude towards the IPM management practice however was negatively related to the willingness to pay for the FCM package but only at 10 percent level.

Table 3: Factors affecting willingness to pay for ACT/HLB and FCM

\begin{tabular}{|c|c|c|c|c|}
\hline \multirow[b]{2}{*}{ Variables } & \multicolumn{2}{|c|}{ ACT/HLB } & \multicolumn{2}{|c|}{ FCM } \\
\hline & Coef. & $\mathbf{Z}$ & Coef. & $\mathbf{Z}$ \\
\hline \multicolumn{5}{|l|}{ Household characteristics } \\
\hline Age of household head (years) & -31.73 & -0.86 & -35.14 & -0.96 \\
\hline Education level of household head(schoolyears) & 206.51 & $1.72 *$ & 204.63 & $1.73 *$ \\
\hline Gender of household head (male) & 550.85 & 0.64 & 601.16 & 0.70 \\
\hline Household size (adult equivalent) & 320.27 & 1.56 & 377.74 & 1.85 \\
\hline \multicolumn{5}{|l|}{ Household resources } \\
\hline Proportion of farm income from citrus (\%) & 32.16 & $2.10 * *$ & 21.24 & 1.39 \\
\hline Proportion of loss by ACT/HLB (\%) & -46.82 & -0.68 & & \\
\hline Proportion of loss by FCM (\%) & & & -17.41 & -0.45 \\
\hline Land under citrus (acres) & -295.50 & $-2.69 * * *$ & -296.22 & $-2.65 * * *$ \\
\hline \multicolumn{5}{|l|}{ Household access to services } \\
\hline Distance to credit source (walking minutes) & -0.27 & -0.06 & -1.87 & -0.41 \\
\hline Extension officer contact (dummy) & 2598.30 & $2.88 * * *$ & 2129.54 & $2.39 * *$ \\
\hline \multicolumn{5}{|l|}{ Knowledge, attitude and practice scores } \\
\hline Knowledge score for ACT/HLB (\%) & 8.10 & 0.36 & 57.96 & $2.87 * * *$ \\
\hline Attitude score $(\%)$ & -47.64 & -0.45 & -96.47 & $-1.78 *$ \\
\hline Practice score (\%) & -34.57 & -0.81 & 22.89 & 0.43 \\
\hline Use synthetic pesticides (dummy) & 299.24 & 0.20 & 388.39 & 0.26 \\
\hline \multicolumn{5}{|l|}{ Social capital networks } \\
\hline Have contract for citrus (dummy) & -176.03 & -0.05 & -702.41 & -0.18 \\
\hline Constant & -21.30 & -0.01 & 877.46 & 0.25 \\
\hline Number of Observations & 324 & & 324 & \\
\hline $\mathrm{P}>\mathrm{chi} 2$ & 0.0022 & & 0.0025 & \\
\hline Log likelihood & -333.268 & & -333.198 & \\
\hline
\end{tabular}

\section{CONCLUSION AND RECOMMENDATIONS}

The objective of this study was to assess the willingness for pay for IPM measures for addressing some of the devastating citrus pests and diseases in Kenya. These are False coding moth (FCM) and African Trioza (ACT) that vectors the greening disease. The study was carried out ex ante implementation of the IPM measures in purposively selected areas in Kenya where citrus production is predominant. These are Machakos and Makueni county. The study further estimated the factors that are likely to influence the willingness to pay for these IPM measures. Both descriptive and regression analysis were utilized using a randomly selected sample of citrus growing households from the two counties. Contingent Valuation technique was applied to elicit WTP for the IPM measures, using the double bounded approach. The results show that on average, farmers were willing to pay KES 7, 766 and 10,638 per acre per season for the FCM and ACT/HLB IPM packages respectively. This was $40 \%$ and $105 \%$ over and above the cost of standard IPM packages for FCM and ACT/HLB respectively, revealing potential demand for the IPM packages. Farmers would be willing to try the new technology in place of conventional pesticides.

Important factors that influence the WTP for the IPM measures include education of the household head, proportion of household income derived from citrus, and land under citrus crop, extension contact, and knowledge and attitude scores. All these factors were positively related to the WTP for the IPM measures except land under citrus and attitude score. From a policy perspective, there is need to increase awareness on the use of IPM technologies among the citrus producers as an alternative method for management of FCM, ACT and greening disease. This can be achieved through building capacity of the extension officers to deliver accurate and timely information to the farmers.

Given that the study utilized one-time survey data, future studies could consider using panel data. Moreover, 
a follow up study, after introduction of the IPM strategies, should be considered to access whether farmer's knowledge would influence their willingness to pay for the strategies, as well as understanding of the factors that enhance farmer's willingness to pay for the strategy. This survey only covered one citrus producing region in Kenya (Machakos and Makueni), similar surveys in other citrus production areas such as those in the coast province are therefore paramount, to evaluate farmers' opinions which may vary across cultural, and socioeconomic, and agro-ecological conditions. Furthermore, further research will be required to establish the costs and benefits of the IPM strategies among the resource constraint small-scale farmers, to understand the feasibility of the strategy among the small citrus growers.

\section{REFERENCES}

Adetonah, S., Coulibaly, O., Nouhoheflin, T., Kooyman, C., \& Kpindou, D. (2008). Farmers' Perceptions and Willingness to Pay for Metarhizium-based Bio pesticide to Control Cotton Bollworms in Benin (West Africa). Presented at the 2007 Second International Conference, August 20-22, 2007, Accra, Ghana, African Association of Agricultural Economists (AAAE).

Blake, G., Sandler, H., Coli, W., Pober, D., \& Coggins, C. (2007). An assessment of grower perceptions and factors influencing adoption of IPM in commercial cranberry production. Renewable Agriculture and Food Systems, 22(02), 134-144.

Bové, J. M. (2006). Huanglongbing: a destructive, newly-emerging, century-old disease of citrus. Journal of Plant Pathology, 7-37.

Carson, R. T., Flores, N. E., \& Meade, N. F. (2001). Contingent valuation: controversies and evidence. Environmental and Resource Economics, 19(2), 173-210.

Charleston, D. S., Kfir, R., Rensburg, N. van, van Barnes, B. N., Hatting, V., \& Conlong, D. E. (2003). Integrated pest management in South Africa. Integrated Pest Management in the Global Arena, 169-195.

Flachaire, E., \& Hollard, G. (2006). Controlling starting-point bias in double-bounded contingent valuation surveys. Land Economics, 82(1), 103-111.

González, C., Johnson, N., \& Qaim, M. (2009). Consumer acceptance of second - generation GM Foods: The case of bio fortified cassava in the North - east of Brazil. Journal of Agricultural Economics, 60(3), 604624.

Hanemann, M., Loomis, J., \& Kanninen, B. (1991). Statistical efficiency of double-bounded dichotomous choice contingent valuation. American Journal of Agricultural Economics, 73(4), 1255-1263.

Hanemann, M. W., \& Kanninen, B. (1998). The statistical analysis of discrete-response cv data, California agricultural experiment station giannini foundation of agricultural economics. Department of Agricultural and Resource Economics and Policy. University of California, Berkeley, CA.: Working Paper 798.

Jaetzold, R., Schmidt, H., Hornet, Z. B., \& Shisanya, C. A. (2006). Farm Management Handbook of Kenya. Natural Conditions and Farm Information (Eastern Province).

Kassie, G. T., Abdulai, A., Greene, W. H., Shiferaw, B., Abate, T., Tarekegne, A., \& Sutcliffe, C. (2017). Modeling Preference and Willingness to Pay for Drought Tolerance (DT) in Maize in Rural Zimbabwe. World Development, 94, 465-477. https://doi.org/10.1016/j.worlddev.2017.02.008

Kibira, M., Affognon, H., Njehia, B., Muriithi, B., Mohamed, S., \& Ekesi, S. (2015). Economic evaluation of integrated management of fruit fly in mango production in Embu County, Kenya. African Journal of Agricultural and Resource Economics Volume, 10(4), 343-353.

Kimenju, S. C., \& De Groote, H. (2008). Consumer willingness to pay for genetically modified food in Kenya. Agricultural Economics, 38(1), 35-46.

Lusk, J. L., \& Hudson, D. (2004). Willingness-to-pay estimates and their relevance to agribusiness decision making. Applied Economic Perspectives and Policy, 26(2), 152-169.

Manene, S. K. (2010). Technology on Reducing Post-harvest and Maintaining Quality of Fruits and Vegetables in Kenya. In Technology on Reducing Post-harvest Losses and Maintaining Quality of Fruits and Vegetables: Proceedings of 2010 AARDO Workshop (pp. 141-144).

Ministry of Agriculture Annual Report ( 2010)

Muchiri, C. M. (2012). Economic assessment of losses due to f.ruit fly infestation in mango and the willingness to pay for an integrated pest management package in Embu district, Kenya.

Muriithi, B. W., Affognon, H. D., Diiro, G. M., Kingori, S. W., Tanga, C. M., Nderitu, P. W., ... Ekesi, S. (2016). Impact assessment of Integrated Pest Management (IPM) strategy for suppression of mangoinfesting fruit flies in Kenya. Crop Protection, 81, 20-29.

Norton, G. W., Rajotte, E. G., \& Gapud, V. (1999). Participatory research in integrated pest management: Lessons from the IPM CRSP. Agriculture and Human Values, 16(4), 431-439.

Sastry, K. S., \& Zitter, T. A. (2013). Plant virus and viroid diseases in the tropics. Springer.

Urquhart, P. (1999). IPM and the citrus industry in South Africa. Sustainable Agriculture and Rural Livelihoods Programme, International Institute for Environment and Development. 
Varela, A. M., Seif, A., \& Nyambo, B. (2006). A guide to IPM in mango production in Kenya. ICIPE, Nairobi, Kenya.

Whitehead, J. C. (2002). Incentive incompatibility and starting-point bias in iterative valuation questions. Land Economics, 78(2), 285-297 